\title{
EL ÁMBITO PENAL DE LA JURISDICCIÓN PLENA DE LOS PUEBLOS ORIGINARIOS: ELEMENTOS PARA SU ANALISIS DESDE EL MARCO DEL CONSTITUCIONALISMO GARANTISTA
}

\author{
The full scope of criminal jurisdiction of native people: \\ Elements for analysis from under the guarantor constitutionalism
}

\author{
Julio Cesar KALA \\ Isis Nevai ALBARRÁN GARCÍA* \\ Martha Paola FERNÁNDEZ LOZANO**
}

\begin{abstract}
Sumario:
I. Derecho de autodeterminación de los pueblos originarios. II. La necesidad de reestructurar el pacto federal fundado en un modelo garantista. III. Orientación de la política criminal en México. IV. Hacia una política criminal garantista. V. Discusión. VI. Fuentes de consulta.
\end{abstract}

Resumen:Las demandas de los pueblos originarios por el respeto pleno a su identidad cultural, en la que se encuentra la jurisdicción penal, son uno de los litigios que enfrenta el Estado de Derecho contemporáneo como modelo político jurídico. Es necesario el cambio de paradigma constitucional para impulsar una política de respeto pleno a los derechos de todos, para resolver racionalmente estas controversias se requiere, inicialmente que el proyecto político y el modelo teórico del Estado mexicano se adecuen al constitucionalismo garantista y secundariamente el alineamiento de la legislación y de la operación jurídica a los principios de éste.

Palabras Clave: Derechos Humanos, pluriculturalidad, pueblos originarios, jurisdicción penal, Pacto Federal, política criminal

Abstract: The demands of the indigenous people for the full respect of their cultural identity, in which the criminal jurisdiction is included, is one of the disputes contemporary Rule of Law is facing now as a legal political model. The change of the Constitutional Paradigm is needed to promote a full respect policy of all people's rights. To rationally solve these disputes, is required

\footnotetext{
${ }^{1}$ Dr. en Ciencias penales por el Instituto Nacional de ciencias Penales, México; profesor titular “B”, por oposición, de la Universidad de Guanajuato adscrito al Departamento de Derecho; miembro del Sistema Nacional de Investigadores; responsable del Cuerpo Académico Ciencia penal, Estado de derecho y Derechos humanos; Secretario Técnico del Doctorado Interinstitucional de Derecho de la región centro-occidente del ANUIES; Líder del proyecto de investigación Jurisdicción Plena de los Pueblos Originarios en el Ámbito de la Política Criminal.

* Mtra. en Administración y Procuración de Justicia por la Universidad Autónoma de Chihuahua; Especialista en Derecho Procesal Civil por la Universidad de la Salle Bajío; Directora del Centro Multidisciplinario de Atención Integral a la Violencia, Sistema DIF, León; Integrante del proyecto de investigación Jurisdicción Plena de los Pueblos Originarios en el Ámbito de la Política Criminal.

${ }^{*}$ Alumna de la Licenciatura en Derecho de la Universidad de Guanajuato; Miembro del Programa Estudiantil de Investigaciones Jurídicas de la División de Derecho, Política y Gobierno de la Universidad de Guanajuato; Integrante del proyecto de investigación Jurisdicción Plena de los Pueblos Originarios en el Ámbito de la Política Criminal.
} 
first that the Mexican Rule of Law's theorical model and political project fit the guarantor constitutional model; and secondly, the alignment of the legislation and legal operation to the principles of this.

Keywords: Human rights, multiculturalism, Indigenous peoples, criminal jurisdiction, Federal Pact, criminal policy.

\section{DERECHO DE AUTODETERMINACIÓN DE LOS PUEBLOS ORIGINARIOS}

El Estado contemporáneo atraviesa una profunda crisis estructural. Por un lado, entre los procesos de integración global, la autonomización regional y la identidad nacional, así como la violencia internacional ejercida por las instancias de poder supranacionales del mercado que amenazan la esfera política jurídica de los estados, particularmente de los más vulnerables; ${ }^{2}$ por otro, la añeja idea de Estado nación y la consecuente confrontación con la conformación multicultural de países en los que las minorías étnicas aclaman su derecho al reconocimiento de su identidad cultural. ${ }^{3}$

En países colonizados, como el nuestro, en el que la política colonizadora no se orientó hacia el exterminio de los pueblos originarios, el mosaico poliétnico y multicultural de la población actual marca los retos de los Estados con anhelos constitucionales. Esta conformación en la que las minorías étnicas reclaman el derecho al ejercicio pleno de su identidad cultural ha generado tensiones con el Estado de derecho, particularmente en el ámbito penal, ya que en ocasiones se confrontan los sistemas jurídicos de los pueblos originarios con el derecho positivo mexicano.

Lo indígena como categoría nace con la colonia, antes del encuentro entre el viejo y nuevo mundo, no existían indios, ${ }^{4}$ los autóctonos contaban con medios de impartición de justicia propios, con la colonización surge la diferenciación y su subordinación a los sistemas jurídicos de los colonizadores.

A raíz de la conquista la población indígena del continente americano fue segregada y devaluada, quedando en una posición de desigualdad frente a sus conquistadores y solo con la evolución los derechos humanos se le ha ido reconociendo sus derechos, entre ellos el de su identidad nacional. Éste, puede considerarse como el antecedente del derecho a la autonomía de los pueblos originarios, y por tanto de la jurisdicción plena como atributo de la soberanía. ${ }^{5}$ Sin embargo, en la mayoría de los países latinoamericanos los pueblos indígenas no han materializado cabalmente este derecho.

En América latina el proceso de inclusión en las constituciones ha sido lento, sólo se ha reconocido la diversidad cultural desvinculada del ejercicio del propio derecho, limitando así la jurisdicción plena. Entre los problemas a los que se enfrentan los pueblos originarios

\footnotetext{
${ }^{2}$ FERRAJOLI, Luigi (2011), Principia Iuris. Teoría del Derecho y de la Democracia, Tomo 2 Teoría de la Democracia, Trotta, Madrid, España, p. 540.

${ }^{3}$ CARBONEL, Miguel (2001), "Estudio introductorio" en Cosmopolitismo, estado-nación y nacionalismo de las minorías. Un análisis crítico de la literatura reciente, KYMLICKA, Will y STRAEHLE, Christine, Universidad Nacional Autónoma de México, México, p. 20.

${ }^{4}$ CEBALLOS BEDOYA, Nicolás (2011), "Usos indígenas del derecho en el Nuevo Reino de Granada, resistencia y pluralismo jurídico en el derecho colonial. 1750 - 1810" en Revista Estudios Socio - Jurídicos, 13 (2), p. 227.

${ }^{5}$ Como autodeterminación nacional reconocida en el espectro poliétnico y multicultural de Estados como el mexicano. Que tendría que denominarse como Estados multinacionales, por la integración de los pueblos originarios.
} 
se encuentra la inexistencia del reconocimiento de sus derechos culturales en las constituciones, o en su caso, la inadecuada redacción de los mismos. El desconocimiento de la teoría constitucional funge un papel muy importante ya que la redacción de la Carta Magna y su posterior aplicación práctica exige una técnica y [una] metodología específicas. Las carencias en este sentido generan ineficacia e inseguridad. ${ }^{6}$

México es un país poliétnico y multicultural como se reconoce en el artículo $2^{\circ}$ Constitucional. En el año 2000 según el Instituto Nacional de Estadística y Geografía e Informática (INEGI) la población indígena en nuestro país ascendía aproximadamente al seis por ciento del total, mientras que para la Comisión Nacional para el Desarrollo de los Pueblos Indígenas ${ }^{7}$ existía una población de entre el 10\% y el 14\%; en el sitio web de esta dependencia se contemplan 10'220,000 indígenas en el país, lo que constituiría cerca del 11\% por ciento de la población mexicana, en esta población se consideran 65 grupos étnicos, la mayor parte asentados en los estados de Chiapas, Guerrero, Oaxaca, Yucatán y Quintana Roo.

Entre los eventos jurídicos más importante de la historia de México que han marcado a nuestros pueblos originarios, se encuentran: la política indigenista surgida en la Revolución, el reconocimiento en el artículo $4^{\circ}$ constitucional de la pluriculturalidad del estado en $1992 ;^{8}$ la reforma al artículo $2^{\circ}$ respecto a la libre determinación y autonomía para las comunidades y pueblos indígenas del 2001, ${ }^{9}$ la reforma de derechos humanos con la introducción del principio pro persona del $2011^{10} \mathrm{y}$ finalmente, la resolución de la Suprema Corte de Justicia de la Nación en la que resolvía que los tratados internacionales, suscritos por México, quedaban restringidos cuando fueran contrarios a la Carta Magna. ${ }^{11}$

Simultáneamente los movimientos indígenas, demandan acceso a la justicia y el reconocimiento pleno a su identidad cultural: jurisdicción plena en todos los ámbitos de sus sistemas jurídicos, autonomía y siguiendo al ex relator de las Naciones Unidas, James Anaya, a que se rijan económica, social y culturalmente plenamente en el ejercicio de sus derechos históricos.

A contrapelo, en estos escenarios se ha identificado la autonomía de los pueblos originarios con la separación normativa, se ha difundido la idea de que el respeto pleno de los sistemas normativos de los pueblos originarios se contrapone con la Constitución y que sus demandas discrepan con la soberanía y menguan la unidad del Estado Mexicano, como si fuera posible suponer la existencia de un conflicto entre derechos; ${ }^{12}$ ante esto es importante plantearnos lo siguiente:

${ }^{6}$ FERNÁNDEZ RODRÍGUEZ, José Julio y ARGUELLO LEMUS, Jacqueline (2012),"Aspectos constitucionales del multiculturalismo en América Latina: el caso de los pueblos indígenas", en Revista Pensamiento Constitucional, No. 16, p. 124.

${ }^{7}$ Antes Instituto Nacional Indigenista (INI).

${ }^{8}$ Diario Oficial de la Federación de fecha 28 de enero de 1992.

${ }^{9}$ Diario oficial de la federación de fecha 14 de agosto del 2001.

${ }^{10}$ Diario Oficial de la Federación de fecha 10 de junio de 2011.

${ }^{11}$ DERECHOS HUMANOS CONTENIDOS EN LA CONSTITUCIÓN Y EN LOS TRATADOS INTERNACIONALES. CONSTITUYEN EL PARÁMETRO DE CONTROL DE REGULARIDAD CONSTITUCIONAL, PERO CUANDO EN LA CONSTITUCIÓN HAYA UNA RESTRICCIÓN EXPRESA AL EJERCICIO DE AQUÉLLOS, SE DEBE ESTAR A LO QUE ESTABLECE EL TEXTO CONSTITUCIONAL. Contradicción de Tesis. P./J. 20/2014. Publicación: viernes 25 de abril de 2014.

${ }^{12}$ En las democracias es inexistente un conflicto entre derechos, la ampliación de la esfera de derechos de una persona implica indefectiblemente la ampliación de los derechos de todos los demás. Por ejemplo, suponer que existe conflicto entre el derecho a la libre manifestación respecto del libre tránsito y argumentar que uno prevalece sobre otro en una circunstancia dada, como lo planteó la Suprema Corte de Justicia de la Nación en 
[L]a autonomía en cualquier escala, como ejercicio de la autodeterminación, supone al menos cuatro elementos esenciales; 1) una base "político-territorial»; 2) una «jurisdicción» propia, correspondiente al ámbito territorial indicado, en término de la cual se ejerce gobierno y justicia; 3) un «autogobierno» (gobierno autónomo), definido como un orden de autoridad específica y constituido del sistema de poderes verticales que conforma la organización del Estado; 4) unas «competencias» o facultades propias, exclusivas o compartidas con otras instancias de gobierno, que configuran la descentralización política consustancial a cualquier régimen autonómico. Todo ello consagrado constitucional y legalmente como parte del régimen jurídico del Estado. ${ }^{13}$

Ferrajoli refiere que los derechos sociales imponen deberes de hacer; en México se ha negado de facto lo que en el discurso se acepta; se han desarrollado sin ningún proyecto garantista por medio de una caótica acumulación de leyes, aparatos y prácticas políticoadministrativas; ${ }^{14}$ en lugar de crear los instrumentos adecuados para dar solución ha ignorado las lagunas de garantía y remarcado los aparentes conflictos entre derechos.

A los pueblos originarios se les ha negado personalidad para ser partícipes del pacto, no han sido considerados como sujetos de derecho público y por esto no tienen la capacidad de ser sujetos colectivos de derechos y obligaciones. La sociedad se encuentra inmovilizada por la camisa de fuerza que fue tejiendo el gobierno [...], esta plataforma constitucional y legal [impide] cualquier intento de establecer un régimen de autonomía en México. ${ }^{15}$

En nuestro país existe una fuerte tendencia a legislar a favor de los derechos humanos pero con una intensa práctica de incumplimiento de los mismos. ${ }^{16}$

El Estado constitucional debe ser promotor y garante de los principios del modelo teórico y de las prácticas del proyecto político en el que se funda y debe estar atento a los retrocesos de alguno de estos dos aspectos, pues así como en algún momento se creyó que la pluriculturalidad plasmada en la reforma Constitucional de 1992 sería suficiente, que una verdadera trasformación vendría con la reforma del 2001, o que la reforma en materia de Derechos

los expedientes 96/2014 y 97/2014 que aún se encuentran pendientes de resolver, implica de facto reconocer que a quienes se les confiere el ejerció del derecho, en éste caso a los manifestantes, son ciudadanos de primer nivel y a quienes se les obstaculiza su derecho en esta misma situación a los automovilistas y transeúntes son ciudadanos de segundo nivel. Problemas tan complejos como éste son resueltos frecuentemente en sociedades democráticas sin mayores contratiempos por oficiales de la policía quienes en el marco de sus funciones velan por el derecho de todos y procuran al mismo tiempo el derecho a la libre manifestación y el derecho al libre tránsito, con lo que al permitirse el derecho de uno se asegura el derecho del otro, como tiene que ser en las democracias.

${ }^{13}$ DÍAZ POLANCO, Héctor (2007), La Rebelión Zapatista y la Autonomía, Siglo Veintiuno Editores, México, p. 208.

${ }^{14}$ Para Ferrajoli la tutela efectiva de los derechos sociales ha quedado confiada al welfare, lo que implica que los problemas suscitados se deban a la falta de mecanismos adecuados de garantía. Estos mecanismos conllevan la máxima desburocratización de las estrategias, pues a lo que se debe atender es a la lógica universalista de los derechos fundamentales. Véase: FERRAJOLI, Luigi (2010), Derechos y garantías: la ley del más débil, Trotta, Madrid, España, p. 111.

${ }^{15}$ La pregunta crucial es si este marco normativo permite el reconocimiento efectivo de la autonomía en nuestro sistema jurídico. DÍAZ POLANCO, Héctor, Op. Cit., nota 12, p. 167.

${ }^{16}$ Con esto, además, Beauchot señala que si la filosofía que de Derechos Humanos se hace en México es de resistencia, es porque "nuestra realidad es una violación sistemática e impune de los derechos humanos". BEAUCHOT, Mauricio, Interculturalidad y Derechos Humanos (2003), Siglo Veintiuno Editores, México, p. 52 . 
Humanos del 2011 configuraba un gran avance, esto no ha sido suficiente para que el Estado garantice de facto la jurisdicción plena de los pueblos originarios.

No se trata de resolver sólo un problema normativo sino de la tutela efectiva de derechos. Resolver sobre su autonomía, sobre la jurisdicción plena de los pueblos originarios es un asunto de reconocimiento auténtico y de interpretación correcta de la ley, al amparo de los principios de un Estado constitucional garantista resolviendo las contradicciones y eliminando las lagunas en la ley, suponer conflictos entre pluriculturalidad y soberanía con el derecho positivo implica fracturar de facto los principios del constitucionalismo garantista.

El movimiento indígena no acepta una legislación que simule el reconocimiento de los pueblos originarios pero que en realidad lo niega, que extiende prerrogativas para impulsarlos y a su vez los constriñe al derecho positivo en detrimento de su identidad cultural. Las reformas, así como las políticas y los programas hasta hoy manejados y propuestos propagan la sombra del empobrecimiento ${ }^{17}$ cuyo apoyo se sustenta en la intensa publicidad que esconde la estancada realidad y la fatalidad que la inoperatividad del Estado ha dejado para ellos.

\section{LA NECESIDAD DE REESTRUCTURAR EL PACTO FEDERAL FUNDADO EN UN MODELO GARANTISTA}

El modelo de Estado-Nación mexicano, como los occidentales, es contractual, supone una asociación de individuos unidos voluntariamente para disminuir el ejercicio de la violencia individual y proteger la vida, la integridad y los bienes de los asociados.

Las teorías contractualistas ${ }^{18}$ clásicas refieren la uniformidad institucional y jurídica del Estado, por ello de los justiciables y del aparato administrativo. En sus orígenes el Estado de Derecho moderno ${ }^{19}$ impone un orden sobre la compleja diversidad de los habitantes de las sociedades que lo componen, de manera que el Estado-nación soberano se orienta hacia la homogeneidad como sinónimo de igualdad. ${ }^{20}$

El pacto federal en el prototipo del Estado de derecho, persigue estos mismos fines. Este pacto no sólo se refiere al corpus normativo sino también a las instituciones en general, a la estructura básica de la que hablaba Rawls, esas instituciones que de forma dominante y desde el inicio de toda vida humana, determina las oportunidades vitales de las personas. ${ }^{21}$ Aunque sí, esta normatividad constitucionaliza o legaliza las instituciones y tendenciosa-

\footnotetext{
${ }^{17}$ DÍAZ POLANCO, Héctor, Op. Cit., nota 12, p. 151.

${ }^{18}$ HOBBES (1651), LOCKE (1662), ROUSSEAU (1762), KANT (1786), entre otros.

${ }^{19}$ Véase: KANT, Immanuel 1786, (1968) Principios metafísicos de la doctrina del Derecho, Universidad Nacional Autónoma de México, Dirección General de Publicaciones, Col. Nuestros Clásicos, No. 33, Serie Filosofía, México.

${ }^{20}$ En sus orígenes en las sociedades Europeas la igualdad política-jurídica se fundaba en la igualdad cultural. En los estados poliétnicos y multiculturales como el nuestro la igualdad política, y por ende jurídica implica el reconocimiento y el respeto a la diversidad de la identidad cultural de las sociedades que lo integran.

${ }^{21}$ RAWLS, John, Teoría de la Justicia (2010), trad. María Dolores Gonzáles, Fondo de Cultura Económica, México, p. 149.
} 
mente pretende legitimarlas. En los Estados constitucionales conformados poliétnica y multiculturalmente es necesario asegurar el ejercicio de la soberanía de los pueblos originarios.

En el Estado moderno de derecho la soberanía es un poder legítimo sometido al imperio de las normas jurídicas, la Constitución no puede más que expresar el resultado de un convenio asumido libremente por todos, orientada a preservar las decisiones de todos. ${ }^{22}$

En la conformación del Estado mexicano los indígenas no han sido partícipes, en términos de las teorías contractualistas, del modelo teórico ni en el proyecto político. En el modelo de Estado-Nación actual en México los indígenas no han tenido cabida, debido a la falsa idea de que sus derechos contravienen al pacto federal, no se les reconoce de facto la personalidad jurídica contemplada en la Constitución, han sido considerados más como sujetos de tutela que como actores políticos. Reconocer la autonomía de los pueblos originarios termina con la mala práctica de incorporar al indio a la cultura nacional mediante sistemas de asimilación o a través de imposición de proyectos para que se incorporen a la dinámica social, ${ }^{23}$ sin considerar que son pueblos autónomos y con derecho al ejercicio pleno de su jurisdicción.

En términos de Rawls, la estructura básica no puede construirse para un determinado grupo de personas, que estereotipe y norme las necesidades y derechos del resto de los individuos, pues esto es incompatible con la naturaleza de los derechos humanos. ${ }^{24}$

Sin embargo para que del análisis del artículo $2^{\circ}$ constitucional se desprenda que éste es el fundamento legal de la pluriculturalidad y esbozo del reconocimiento de la personalidad jurídica de los pueblos originarios se requiere reconocer la necesidad de reestructurar el pacto federal ${ }^{25}$ en los términos de un Estado constitucional garantista.

Esta reestructuración del pacto federal deberá estar fundada en un constitucionalismo garantista que permita a los pueblos originarios ejercer su soberanía y con ello la plena jurisdicción, por ejemplo en materia penal, para lo cual será necesario dar un giro en las políticas criminales que rigen nuestro país, persistiendo la necesidad de que sea una política criminal garantista la que guíe al derecho penal.

\section{ORIENTACIÓN DE LA POLÍTICA CRIMINAL EN MÉXICO}

Las consecuencias de la orientación actual de la política criminal saltan a la vista. Desde la perspectiva democrática, la formalización del relajamiento constitucional por sí mismo propicia el debilitamiento del Estado democrático. Considerar al Derecho como primera ins-

\footnotetext{
${ }^{22}$ Aunque este acuerdo no es asumido particularmente desde el nacimiento, sí debería prospectar los principios que aceptarían todos sus individuos, a razón de que al nacer ya están determinados a las instituciones que determinan a la sociedad de su contexto; esto no se logra si las máximas que direccionan el pacto responden a lógicas que subsumen a las minorías por decisión o bienestar de las mayorías.

${ }^{23}$ GÓMEZ MADRIGAL, Laura Sofía (2012), La protección jurídica de los conocimientos tradicionales desarrollados por las comunidades indígenas en México el caso de la medicina tradicional. (Tesis doctoral inédita), Doctorado Interinstitucional de Derecho. Universidad Michoacana de San Nicolás de Hidalgo, p. 20.

${ }^{24}$ En la Teoría de la Justicia de John Rawls, la estructura básica es el objeto de la justicia social, pues son los efectos de esa estructura (los resultados del actuar de las instituciones) los que permiten tener una concepción pública de la justicia, esta concepción pública conlleva al orden del que las teorías contractualistas hablan. La aceptación de esas instituciones dependerá de que respondan a los principios de justicia de un convenio justo. Para ahondar en el tema véase: RAWLS, John, Op. Cit., nota 20.

${ }^{25}$ ESCALANTE BETANCOURT, Yuri (2002), "La reforma constitucional indígena: retomando el camino", en Los Derechos indígenas y la reforma constitucional en México, México, p. 79.
} 
tanci $\mathrm{a}^{26}$ en la solución de conflictos sociales, revela candidez, ignorancia o autoritarismo, ya que no sólo no los resuelve, los potencia y genera más, amén de impedir la participación de instituciones sociales y gubernamentales que intervienen más rápida y eficientemente. Esto, es reconocer el fracaso gubernamental y social en la construcción de escenarios y generación de dinámicas sociales orientados a ampliar la esfera de derechos de todos los grupos sociales. Asimismo, lleva a la postre a un callejón sin salida: ¿A qué recurrir? cuando el Derecho Penal no resuelve el conflicto, como hasta ahora ha sucedido, si éste es la última opción, ¿qué queda? ¿recrudecerlo aún más?

La democracia constitucional y el Estado de derecho mismo se encuentran a punto de crisis o aún peor, de ruptura, debido principalmente a dos fenómenos, el desarrollo de la ilegalidad en el ejercicio de los poderes públicos normativos que se manifiesta en las violaciones de garantías y con ello la producción de antinomias; y el defecto de la legalidad que se expresa en la ausencia de garantías y con ello en la existencia de lagunas.

Las razones de la crisis son múltiples, la falta de introducción de las garantías a la altura de los nuevos poderes y problemas legales, el hecho de que la política no ha aceptado su sujeción al derecho, la pérdida de memoria de las tragedias del pasado, la reducción del papel del gobierno y de garantías de la esfera pública; y la crisis económica, por la abierta subordinación de la política a la economía.

La crisis de la democracia en su dimensión sustancial, es decir los límites y vínculos que deben existir para garantizar los derechos fundamentales frente a cualquier poder está induciendo a un proceso deconstituyente que se manifiesta en el obsoleto principio de sujeción a la ley, tanto de los poderes políticos como de los económicos en los diversos niveles del derecho

En la era de la globalización el futuro de cada país depende cada vez menos de la política interna y más de decisiones externas, adoptadas en sedes extra estatales por las grandes concentraciones económicas y financieras y por las políticas de las mayores potencias, merced a esta subcultura anti-constitucional o cuando menos a-constitucional, se ha hecho frente a la crisis económica mediante la reducción, bajo la etiqueta de reformas, de las garantías de los derechos sociales, con el consiguiente aumento de las desigualdades y la degradación del espíritu público y la cohesión social.

En el derecho y las relaciones internacionales, la crisis de la capacidad regulativa del derecho está manifestándose sobre todo en el plano internacional, el papel garantista de las constituciones no ha sido compensada con la construcción de una esfera pública a la altura de los procesos de globalización.

El desarrollo de la ilegalidad es bastante rápido y catastróficas sus consecuencias, principalmente en la democracia, en el área social y humanitaria, en el plano ambiental, en materia nuclear y en el área criminal las cuales están destinadas a agravarse a no ser que se produzca un giro radical en la economía, en la política y en el derecho.

Esta crisis de la política es la causa primera de todas las crisis mencionadas siendo sus consecuencias la creciente inadecuación del derecho como instrumento de regulación de los poderes, tanto públicos como privados, y de garantía de la igualdad y de los derechos fundamentales de las personas. La actual crisis de la democracia en todas sus formas y dimensio-

\footnotetext{
${ }^{26}$ No sólo a la pretensión preventiva ex ante radicalizada -intervención del Derecho Penal previa a la lesión de bienes jurídicos-, sino a la suposición de que el Derecho Penal inhiba la comisión de delitos. Véase: KALA, Julio César (2005), "Perseverancia en los contenidos penales preventivos", en Seguridad Pública. Voces diversas en un enfoque multidisciplinario, Pedro Peñaloza (Coord.), Porrúa, México.
} 
nes consiste en la impotencia de la política frente a los desafíos globales, en esta perspectiva el constitucionalismo garantista, gracias a la normatividad fuerte asociada a la mayor parte de los principios constitucionales, se revela no sólo como un modelo teórico, sino como un proyecto político de construcción de la democracia.

Una política criminal garantista fundada en un cambio de paradigma constitucional modificaría la estructura del Estado de derecho.

El paradigma constitucional resultante de este cambio estructural puede describirse mediante cuatro principios o postulados:

1. Principio de legalidad, el cual asume una nueva complejidad como principio normativo al mismo tiempo que lógico, conforme al cual en donde quiera que exista un poder, público o privado, ejecutivo, judicial o legislativo, estatal, extra o supra estatal, deberán existir normas primarias, no sólo formales sino también sustanciales, que regulen su ejercicio, sometiéndolo a los límites y a los vínculos de los derechos constitucionalmente establecidos.

2. Principio de plenitud deóntica, en virtud del cual donde quiera que existan derechos o intereses establecidos por normas primarias deberán introducirse como sus garantías primarias los poderes-deberes correspondientes, es decir la prohibición de lesionarlos y la obligación de tutelarlos y satisfacerlos.

3. Principio de jurisdiccionalidad, impone que donde existan normas y garantías primarias deberán existir normas secundarias contra sus posibles violaciones que predispongan la intervención jurisdiccional ya que sin esta intervención resultaría vano el principio de legalidad, y

4. Principio de accionabilidad, conforme al cual donde exista una jurisdicción deberá estar asimismo prevista, como ulterior garantía secundaria, su activación por los titulares de los derechos y de los intereses lesionados y con carácter complementario y subsidiario, por parte de un órgano público capaz de suplir las posibles inercias o debilidades de aquellos.

Estos cuatro principios están concatenados de modo tal, que dado un poder deben existir normas que impongan límites y vínculos, es decir prohibiciones u obligaciones, en garantía de intereses públicos y derechos fundamentales, cuyas violaciones suponen la existencia de una jurisdicción, activable mediante el derecho o el poder de acción. Así pues el modelo garantista de la democracia constitucional se caracteriza por ser un sistema de límites, vínculos y controles impuestos a cualquier poder, en garantía primaria y secundaria de los derechos fundamentales.

En los estados constitucionales, los derechos humanos, los irrenunciables, se ubican en la norma fundamental por el máximo rango, de máxima relevancia, por su máxima fuerza jurídica, por la máxima importancia del objeto y por su máximo grado de indeterminación. ${ }^{27}$ Caracterizar a los derechos fundamentales, los irrenunciables como de máximo rango, no sólo los ubica en la carta magna, sino que califica a las normas que los infrinja como incons-

\footnotetext{
27 Véase: ALEXY, Robert (2005), "Los derechos fundamentales en el Estado constitucional democrático", en Neoconstitucionalismo(s), Miguel Carbonell (Comp.), Trotta, Madrid, España.
} 
titucionales, por ello no es racionalmente posible incluir en la propia constitución normas contrarias a los derechos humanos, ya que son por definición - política, en las democracias- los fundamentos irrenunciables. La máxima fuerza jurídica, que los protege, se extiende a los tres poderes, sólo así es posible salvaguardarlos y reaccionar ex ante a su posible menoscabo. La máxima importancia del objeto, referida a las construcciones sociales más importantes, los identifica con la estructura básica de la sociedad, por ello mismo son derechos fundamentales, imprescindibles. Finalmente su máximo grado de indeterminación, es decir, no identificarlos solamente como aquéllos que explícitamente se encuentran en el corpus de la carta magna, sino en la interpretación de todos aquellos ordenamientos que posibiliten su identificación, cada vez más precisa.

Incluir las excepciones a las garantías en la constitución no es constitucionalizarlas, es desvirtuar la norma fundamental, es inconstitucionalizarla.

El paradigma constitucional garantista tiene como rasgo teórico distintivo su carácter formal, es decir, la estipulación de lo que no puede ser decidido dentro de esta esfera de lo no decidible como la ha llamado Ferrajoli, se encuentran los derechos fundamentales, la positivización de estos derechos somete al legislador a límites y vínculos sustanciales, así la noción de democracia en su modelo garantista puede muy bien articularse en cuatro dimensiones -política, civil, liberal y social- formales las dos primeras y sustanciales las otras dos, en virtud de las cuales ningún poder, sea público o privado, puede derogar los derechos fundamentales y demás principios constitucionalmente establecidos.

\section{HACIA UNA POLÍTICA CRIMINAL GARANTISTA}

La discusión referida al aparente conflicto entre política criminal y derechos humanos se ha centrado preponderantemente en la vulneración de éstos, Se da por sentado la vigencia del Estado de derecho, sin embargo, desde la sociología jurídica, una parte importante de la discusión se ha orientado a su vigencia fáctica. En este contexto pretendo apuntar algunas consideraciones al respecto, si bien por un lado, en las democracias contemporáneas se han logrado conquistas importantes, por otro, aún persisten grandes problemas que es necesario atender.

Estado como formalización jurídica del pacto político surge para proteger a sus asociados de la violencia, de otros individuos ${ }^{28}$ o grupos y para brindar el mayor bienestar posible, por ello, la disminución de la violencia y de sus efectos es uno de sus cometidos esenciales. ${ }^{29}$

Con fundamento en el contrato que lo crea, asumió el monopolio irrestricto de la creación y la aplicación del derecho, subsumiéndose el mismo en esta dinámica. ${ }^{30}$ Por ser una entidad

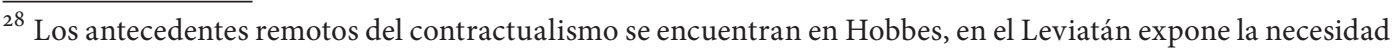
de crear, a través del contrato social, un ente supremo con autoridad tal que pueda impedir la violencia entre particulares. Véase: HOBBES, Thomas, 1651 (2003), Leviatán, Losada, Argentina.

${ }^{29}$ Frente al criterio de autoridad hobbesiano, en el que encuentran fundamento orientaciones totalitarias, Locke subrayó los derechos, naturales, del individuo frente al Estado, por lo que éste se convierte en su garante y su legitimidad se supedita al cumplimiento de este cometido en el marco del reconocimiento de la pluralidad social. Sus ideas sobre la separación de poderes permitirían a Montesquieu elaborar la teoría de la separación de poderes. Locke, John (2005), Ensayos sobre el gobierno civil, Porrúa, México.

${ }^{30}$ [...] la tensión entre regulación y emancipación social se convirtió en un objeto más de la regulación jurídica [...], SOUSA DE, SANTOS Boaventura (2009), Sociología jurídica crítica, Trotta/ILSA, Madrid, España, p.543.
} 
instituida exprofeso para proteger a sus creadores, requiere que el aparato público que le da vida, en caso de ruptura de la norma actúe ejerciendo la violencia mínima indispensable para reaccionar contra el infractor en el despliegue legítimo de la violencia institucional en el ejercicio del ius puniendi.

El reforzamiento del paradigma constitucional garantista, requiere del desarrollo máximo de la dimensión sustancial de la democracia constitucional, a través de las garantías primarias y secundarias de todos los derechos fundamentales, sobre la base del modelo garantista definido mediante los principios de legalidad, plenitud, jurisdiccionalidad y accionabilidad. Es la expansión de cada uno de estos principios frente a cualquier poder nacional y supranacional.

Precisamente la conciencia del carácter irreversible de la globalización y el peligro de desastres irremediables provocado por los actuales poderes desregulados, puede provocar la oportunidad de un sentido nuevo del derecho y del interés general, con una concepción universalista del constitucionalismo y de la democracia fundada en la percepción de los derechos como derechos de todos, reivindicando a escala global una expansión del paradigma garantista de la democracia constitucional.

Para que se produzca un verdadero giro es necesario que el proyecto garantista diseñado por las constituciones, se proponga como proyecto político capaz de rehabilitar el papel de la política, y con ella de legislación, reforzando las garantías primarias de los derechos constitucionalmente establecidos, mediante políticas acordes a este respeto de las garantías constitucionales, no flexibilizándolas para dar una aparente respuesta eficaz a los problemas de impunidad e inseguridad, que en lugar de solucionar agravan esta situación.

Con la aparición del Estado de derecho ${ }^{31}$ se dio un gran paso en la construcción de la democracia, del Estado ilustrado ${ }^{32}$ a sus configuraciones contemporáneas se ha logrado un avance importante. Las expectativas que ofrece este modelo político de organización estatal, por el reconocimiento de los derechos humanos y por los mecanismos creados para su protección y su ejercicio pleno para la construcción de escenarios en los que libertad y seguridad sean el soporte de la vida social, lo han promovido como el modelo político-jurídico de los estados occidentales contemporáneos.

El estadio más desarrollado de este paradigma ${ }^{33}$ se caracteriza por: i) su vinculación a una constitución rígida y ii) las condiciones de validez normativa trascienden la fuente formal de producción dependen, además, sobre todo de su congruencia con el contenido de los principios constitucionales, los derechos fundamentales. Por ello es posible suponer la existencia de una norma válida, consecuentemente vigente, pero sustancialmente inválida, debido a su sentido, a su contenido, a su antagonismo con los principios constitucionales.

\footnotetext{
${ }^{31}$ El Estado kantiano constituye la primera conceptualización de este modelo de Estado:
}

[...] Es menester salir del estado natural, en el que cada cual obra según su antojo y convenir con todos los demás (cuyo comercio es inevitable) en someterse a una limitación exterior, públicamente acordada y, por consiguiente entrar en un estado en que todo lo que debe reconocer como lo suyo de cada cual es determinado por la ley y atribuido a cada uno por un poder suficiente, que no es del individuo, sino un poder exterior. En otros términos es menester ante todo entrar en un estado civil [...]. KANT, Immanuel, Op. Cit., nota 18, p. 141.

32 [...] el Estado es la respuesta histórica al anhelo de conciliar con fundamento en la razón la libertad del hombre expresado en un contrato [...]. ROUSSEAU, Jean-Jacques 1762, (1996), El contrato social, trad. AndebengAbeu Alingue, Panamericana, Santa Fé de Bogotá, pp. 43-48. Por ello uno de los cometidos del estado es proporcionar seguridad a los individuos, en sus bienes y en su persona, así como garantizar el más amplio ejercicio de sus derechos.

${ }^{33}$ Véase: KUHN, T. S. (2007), Estructura de las revoluciones científicas, Fondo de Cultura Económica, México. 
Esta circunstancia altera la función jurisdiccional tradicional, puesto que la aplicación de la ley requiere inicialmente la evaluación de la consistencia de la ley a la luz de los principios constitucionales, ${ }^{34}$ sólo si es constitucionalmente válida, si es congruente con los derechos fundamentales, por ello, la interpretación normativa y, en su caso, la solución de antinomias o lagunas ha de estar orientada por las garantías existentes o de la proyección de aquéllas que falten, por lo que constituyen un juicio sobre la ley misma. ${ }^{35}$

[E]n el Estado constitucional de Derecho la Constitución no sólo disciplina las formas de producción legislativa, sino que impone también a ésta prohibiciones y obligaciones de contenido correlativas unas a los derechos de libertad y las otras a los derechos sociales, cuya violación genera antinomias o lagunas que la ciencia jurídica tiene el deber de constatar para que sean eliminadas o corregidas $[\ldots] .^{36}$

Un Estado constitucional se caracteriza por cinco principios: i) fundamentales de la dignidad humana, ii) de la libertad, iii) de la igualdad, iv) de la estructura del Estado, v) de los fines del Estado de social y democrático de derecho. ${ }^{37}$ Entre los principios fundamentales y los principios relativos a la estructura y fines del Estado existe una estrecha y tensa relación.

La subordinación de la ley a los principios constitucionales representa un aporte importante en la construcción permanente de la democracia contemporánea, impone límites a los derechos constitucionales de las mayorías y configuran otras garantías de los derechos de todos. En este esquema el Derecho alcanza su más alto desarrollo:

[...] por la sujeción a la ley, incluso del poder legislativo, antes absoluto, y por la positivación ya no sólo del ser del Derecho, es decir, de sus condiciones de «existencia», sino

${ }^{34}$ El control difuso de constitucionalidad y el de convencionalidad constituyen su defensa más importante, pero requiere del compromiso de los operadores jurídicos y de la vigilancia ciudadana.

${ }^{35}$ Requisito ausente en el anterior modelo paleo-iuspositivista del Estado legislativo de Derecho. El Estado legal, primer producto del Estado de Derecho, se caracteriza porque la legitimación de la norma es producto de la autoridad legislativa, de la fuente de producción, de la legalidad y de la formalidad de los actos normativos. Sin embargo, de las conquistas que en su momento representó para la consolidación de garantías: certeza y seguridad jurídicas, igualdad ante la ley e independencia del juez, entre otras, la ley no se subordina a los fines del contrato social, a los principios constitucionales. Esta etapa, en su manifestación más extrema, representa una concreción del planteamiento hobbesiano que centra en la autoridad, la estructura y organización social. En esta fase, la inflación legislativa afecta el principio de legalidad y la disfunción producida por la jerga jurídica genera grandes márgenes de discrecionalidad para los jueces, con la consecuente pérdida de certeza, de eficiencia y disminución real de derechos.

${ }^{36}$ FERRAJOLI, Luigi (2005), "Pasado y futuro del Estado de Derecho", trad. Pilar Allegue, en: Neoconstitucionalismo(s), Miguel Carbonell (Comp.), Trotta, Madrid, España.

${ }^{37}$ Alexy, menciona seis principios contemplados en el modelo alemán, alude a la Ley fundamental referida a la constitución alemana, pero sólo expone cinco: i) Principios fundamentales de la dignidad humana art. 1, ii) de la libertad art. 2, iii) de la igualdad art. 3, iv) de la estructura del Estado art. 20 y v) de los fines del Estado de social y democrático de derecho art 28.1. Un artículo que se encuentra cercano a un principio fundamental es el del 20 a, Protección de los fundamentos naturales de la vida. Alexy, Robert, Op. Cit., nota 26, pp. 31-36. 
también de su deber ser, o sea, de las opciones que presiden su producción y, por tanto, de sus condiciones de «validez» $\left[\ldots . .{ }^{38}\right.$

Al margen de estas consideraciones, de facto, el papel garantista de la Constitución es afectado entre otras circunstancias por: i) las peculiaridades de la democracia representativa, ${ }^{39}$ ii) la injerencia de los centros de poder económico en las decisiones de los estados nacionales ${ }^{40}$ y iii) [...] la incapacidad de los gobiernos democráticos de dominar convenientemente los conflictos de una sociedad compleja [...]..$^{41}$

Las democracias constitucionales se caracterizan por la supremacía de los derechos humanos en su ley fundamental, definida ésta, por cuatro tesis: i) máximo rango, ii) máxima fuerza jurídica, iii) máxima importancia del objeto y iv) máximo grado de indeterminación. ${ }^{42}$

La primera tesis: máximo rango de los derechos fundamentales en la estructura normativa del Estado se concreta al ser regulada en la Constitución y por ser ésta la ley máxima, por medio del principio: lex superior derogat legi inferiori, se establece una relación vinculante del derecho Constitucional con el local, confiriéndole vigencia plena, por ello, cualquier norma jurídica que lo infrinja será inconstitucional y consecuentemente nula por regla general. En este sentido y en la materia, los tratados internacionales signados por el Estado serán norma constitucional, debido a que los derechos humanos, por antonomasia no se enuncian limitativamente sino con pretensiones extensivas, hasta lograr el reconocimiento estatal. ${ }^{43}$

Respecto de la segunda tesis, por ser los derechos humanos vinculantes para los ámbitos del ejercicio del poder y para los niveles de gobierno de la administración pública están do-

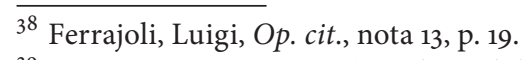

39 CAMOU, Antonio (1995), Gobernabilidad y democracia, Instituto Federal Electoral, Cuadernos de divulgación de la cultura democrática No. 6, México; y Polimeni, Florencia, “¿Democracia representativa vs democracia participativa? La falsa disyuntiva”, en: Democracia participativa, una utopía en marcha. Reflexiones y experiencias y un análisis del caso porteño, Ricardo Romero, Comp., Red de Ciencia Política Mariano Moreno, Argentina, 2005, disponible en: http://bibliotecavirtual.clacso.org.ar/ar/libros/libros/gedep/pdf, consulta 5 de marzo de 2009.

${ }^{40}$ FERRAJOLI, Luigi (2006), “Criminalidad y globalización”, en Boletín Mexicano de Derecho Comparado, No. 115, enero-abril 2006, Instituto de Investigaciones Jurídicas, UNAM, México, disponible en: $h t t p: / / w w w$. juridicas.unam.mx/publica/rev/boletin/cont/115/inf/inf1o.htm.

${ }^{41}$ Asimismo, Bobbio identifica tres circunstancias: i) sobrecargo, incremento de las demandas sociales y la capacidad — limitada - de respuesta del sistema político, ii) conflictualidad propia de las democracias, y iii) distribución del poder. Bobbio, Norberto (1989), Liberalismo y democracia, trad. José F. Santillana, Fondo de Cultura Económica, Breviarios No. 476, México, p. 103.

42 ALEXY, Robert, Op. Cit, nota 26, p. 10.

43 Previsto en el artículo 30 de la Ley Fundamental del Estado Alemán al señalar la prioridad del derecho federal frente a las competencias estatales, Ibidem.

Igualmente identificado en el artículo 133 de la Constitución Política de los Estados Unidos Mexicanos, que señala la supremacía constitucional y la jerarquía normativa de Leyes Federales y Tratados Internacionales, así como la sujeción de las Entidades Federativas a dichas disposiciones. Las recientes reformas, del 10 de junio del 2011, constitucionales en materia de derechos humanos en México, puntualizan aún más esto, en el artículo 105 se refiere:

Las acciones de inconstitucionalidad podrán ejercitarse, dentro de los treinta días naturales siguientes a la fecha de publicación de la norma, por: [...]

g) La Comisión Nacional de los Derechos Humanos, en contra de leyes de carácter federal, estatal y del Distrito Federal, así como de tratados internacionales celebrados por el Ejecutivo Federal y aprobados por el Senado de la República, que vulneren los derechos humanos consagrados en esta Constitución y en los tratados internacionales de los que México sea parte. Asimismo, los organismos de protección de 
tados de la máxima fuerza jurídica. Para el legislativo ya no sólo es necesario reconocer los derechos fundamentales en el marco de las leyes, es imprescindible cambiar el paradigma legislativo, es menester enmarcar la ley en los derechos fundamentales, ${ }^{44}$ para el ejecutivo se demandan líneas de actuación consistentes éstas, por ser derecho positivo y vigente; y para el judicial, los principios constitucionales representan la guía de interpretación y aplicación de la ley, desplegando todo su vigor en la relación de los particulares con el Estado, así como entre los propios particulares. Así, el control se ha de encontrar puntualmente observado por todos los tribunales, del inferior al superior; ya que con una sola disposición constitucional no controlable judicialmente se abre la puerta para la pérdida de su obligatoriedad. ${ }^{45}$

Los derechos fundamentales permean al derecho en su totalidad como juicios de valor objetivos, no obstante de las críticas de su constitucionalización garantizan la realización plena de los fines del Estado.

La tercera tesis, la máxima importancia del objeto, está referida a la estructura básica de las sociedades y al fin del propio Estado, su relevancia estriba en la regulación de derechos específicos considerados como fundamentales, por tanto objeto de protección y reconocimiento constitucional. En este mismo contexto Rawls ${ }^{46}$ concibe a la justicia como equidad, como un modelo democrático, como un sistema de cooperación social constituido por ciudadanos que se conciben como libres e iguales; parte de la idea de un acuerdo mutuo entre participantes que interactúan bajo condiciones equitativas de orden constitucional y político que da forma a la estructura básica de la sociedad. ${ }^{47}$ Con esta definición de justicia Rawls enuncia dos principios: el de la libertad y de la diferencia; el primero, establece que las personas que participan o son afectadas por alguna práctica social tienen el derecho a la más amplia libertad, compatible con una libertad similar para todos; ${ }^{48}$ el segundo, las desigualdades son arbitrarias, a menos que de ella pueda esperarse el beneficio colectivo, siempre y cuando éstas sean igualmente posibles para todos. Estos principios expresan la justicia como

los derechos humanos equivalentes en los estados de la República, en contra de leyes expedidas por las legislaturas locales y la Comisión de Derechos Humanos del Distrito Federal, en contra de leyes emitidas por la Asamblea Legislativa del Distrito Federal [...]. D.O.F., Secretaría de gobernación, México, 10, junio de 2011.

${ }^{44}$ El propio modelo de Estado constitucional limita la producción legislativa en contra de los derechos fundamentales de todos, por ello, para evitar la tiranía de las mayorías, incluso de las unanimidades, el Tribunal Constitucional se erige como árbitro máximo en los conflictos que atenten contra los derechos humanos. Respecto al problema de la aparente paradoja que plantea el binomio mayoría-minoría el control de un poder no-mayoritario, sujeto exclusivamente a la constitución, es imprescindible para dotar de eficacia la subordinación a las disposiciones constitucionales de los poderes mayoritariamente [incluso los unánimemente] legitimados [...]. Véase: GÓMEZ ROMERO, Luis (2004), “¿Jueces guerrilleros? La interpretación judicial desde la izquierda”, en: Juez, Cuadernos de investigación sobre la judicatura, Volumen II, No. 4, primavera 2004, Universidad Iberoamericana, México, p. 29; y ANDRÉS IBÁÑEZ, Perfecto (2001), Ética de la función de juzgar. Ponencia expuesta en el seminario sobre "Ética de las profesiones jurídicas", organizado por la Universidad de Comillas, Madrid, disponible en: http://www.cejamericas.org/doc/documentos/etica-funcion.pdf, consulta 30 de junio de 2009 .

${ }^{45}$ El poder vinculatorio para el ejecutivo es evidente desde el Derecho positivo, el problema radica en el control del legislador, ALEXY, Robert, Op. cit, nota 26, p.33.

${ }^{46}$ RAWLS, John (2003), "Justicia como equidad", en: Revista española de control externo, Vol. 5, № 13, pp. 129158, disponible en: http://dialnet.unirioja.es/servlet/articulo?codigo $=1069286$, consulta 16 de julio de 2010.

47 CACHUMBÉ Holgugín, Nelson (2003), "John Rawls: La justicia como equidad", en Criterio Jurídico, Santiago de Cali, Colombia, $\mathrm{N}^{\circ}$ 3, pp. 7-33, disponible en: http://criteriojuridico.puj.edu.co/archivos/o9_225_nelson_cuchumbe_jhon_rawls.pdf, Consulta 16 julio de 2010, p. 226.

${ }^{48}$ RAWLS, John, Op. Cit., nota 45, p. 131. 
un complejo de tres ideas: libertad, igualdad y recompensa por servicios que contribuyan al bien común $[\ldots] .{ }^{49}$

La cuarta tesis, El máximo grado de indeterminación constituye una de las características fundamentales de este modelo y de los cometidos del Estado. No es posible identificar los derechos fundamentales sólo en la literalidad del texto de la Carta Magna, ${ }^{50}$ éstos se vislumbran a través de la interpretación. [L]a interpretación de la ley fundamental no s[ó]lo suscita meditaciones serenas, sino también confrontación en la arena política. En este sentido, cabe hablar de una lucha por la interpretación de los derechos fundamentales [.....$^{51}$ Los principios de la norma constitucional no se restringen al texto, son la idea general, no existe un significado único previo a la interpretación..$^{52}$

Si bien la democracia se fortalece día a día por medio del reconocimiento de derechos humanos y de la creación de condiciones y mecanismos que posibiliten su ejercicio pleno, estas cuatro máximas revelan, de facto, la solidez de las pretensiones constitucionales de los estados contemporáneos.

Por otro lado, los derechos humanos son conquistas irretroactivas, pertenecen a las democracias contemporáneas, al modelo de Estado occidental, son su fundamento y límite, por ello, los estados nacionales que adoptan este modelo político jurídico no pueden apelar a la soberanía, a la supremacía de la autodeterminación estatal para inclinar la balanza a favor de la seguridad en detrimento de los derechos humanos..$^{53}$

En el terreno de la política criminal, durante las últimas décadas, como se expuso en la primera parte del texto, este modelo de Estado ha sufrido grandes perturbaciones formales que han repercutido en el diseño y aplicación de la política criminal, evidenciando una fuerte crisis del pacto social, ${ }^{54}$ por ejemplo, la instauración de una doble orientación del sistema de justicia penal, una dirigida a la delincuencia convencional y otra a la denominada delincuencia organizada en la que se han flexibilizado las garantías. La lucha por el bien común, fundamento del pacto social, parece haber perdido su significado primigenio, la

\footnotetext{
${ }^{49}$ Idem.

50 [...] en relación con las estructuras de los catálogos no siempre resulta claro si a las diferencias terminológicas puede vincularse una diversa posición respecto de las garantías o jerarquía en cuanto a los niveles de tutela [...]”. ROLLA, Giancarlo (2008), "La actual problemática de los derechos fundamentales", en: Investigaciones Jurídicas, Revista del Departamento de Investigaciones Jurídicas, Facultad de Derecho, Universidad de Guanajuato, Vols., XXII y XXIII, Nums., 80-81, Enero-Diciembre 2006, México, p. 32.

${ }^{51}$ ALEXY, Robert, Op. cit., nota 26, p. 37. En el caso alemán es el Tribunal Constitucional Federal.

${ }^{52}$ En torno a la interpretación in abstracto o in concreto Guastini menciona la necesaria la concurrencia de las dos características, ser in concreto y estar vinculada con la constitución y no in abstracto e inconstitucional, a lo que denomina interpretación adecuadora por ser armónica con el ordenamiento supremo, pero requiere un serio y comprometido ejercicio de reflexión y apego a los principios constitucionales. Guastini, Riccardo (2005), "La constitucionalización del ordenamiento jurídico: el caso italiano", en Neoconstitucionalismo(s), Miguel Carbonell (Comp.), Trotta, Madrid, España, pp. 56 y 57.

${ }^{53}$ Los derechos humanos ahora constituyen un régimen internacional, constituido alrededor de tres documentos y conjuntos de estándares principales: la Declaración Universal de los Derechos Humanos, adoptada el 10 de diciembre de 1948; el Pacto Internacional de Derechos Económicos, sociales y Culturales, vigente desde el 3 de enero de 1976; y el Pacto Internacional de Derechos civiles y Políticos, vigente desde el 23 de marzo de 1976.

54 Santos, identifica tres postulados del contrato social: i) un régimen general de valores, ii) un sistema de medidas y, iii) un espacio tiempo privilegiado. [...] Tal régimen parece hoy en día incapaz de resistir la creciente fragmentación de la sociedad, dividida en muchos <apartheids> polarizada a lo largo de muchos ejes económicos, políticos y culturales [...].SOUSA DE, SANTOS Boaventura, Op. cit., nota 29, p. 552. La política criminal, como concreción de la orientación política del Estado ha promovido estados de exclusión.
} 
polarización promovida por la política criminal obstaculiza la búsqueda de alternativas que enfrenten racionalmente el conflicto penal, con independencia de la categorización establecida, actualmente: convencional-organizada.

La política criminal, aún en un Estado democrático, por ser una política pública, no escapa a estas consideraciones, pero su diseño, implementación y evaluación han de regirse por las directrices emanadas de los fines y cometidos del Estado; ${ }^{55}$ entre ellos los de protección de la persona, al margen de cualquier pretensión instrumental referida a la seguridad. Inscrita en el modelo político-jurídico que orienta el sentido de actuación del poder y del aparato público, esta política pública, referida a lo penal, define las conductas delictivas y los mecanismos de reacción institucional contra ellas a través del Sistema de Justicia Penal.

La política criminal orienta y conforma a un sistema jurídico penal, en el que se integran las tres esferas del poder público y los tres niveles de ejercicio del mismo, en donde la criminología aparece indisolublemente ligada a ella, particularmente por su análisis, en términos del fundamento teórico y operación de las instituciones que conforman este sistema.

[L]a dogmática está traspasada por la política criminal, pues no es más que la derivación conceptual del instrumento formal de definición. Por eso y en forma más precisa, la dogmática penal no puede pensarse como algo autónomo y válido en sí mismo, sino sólo desde la política criminal. Más aún su sentido desde la política criminal es hacer transparente y con fundamentación racional el proceso penal, en cuanto el proceso es uno de los ámbitos básicos en que se ejecuta la política criminal [... ${ }^{56}$

Los estados con pretensiones constitucionales fincan sus relaciones con las personas en el reconocimiento de éstas como entes autónomos, con derechos y garantías, por ello, su programa político criminal ha de estar dirigido a establecer el máximo de espacios para el ejercicio de la libertad; no puede partir de la premisa del imperativo de la norma penal y de su función motivadora, ya que esto revelaría el fracaso del contrato social y el imperio de la violencia institucionalizada, el precepto jurídico simplemente instruye o informa sobre los modelos de comportamiento y sus consecuencias jurídicas. ${ }^{57}$ En las democracias constitucionales, la política criminal no puede configurarse para limitar el ejercicio de los derechos de una persona o eliminarlo en cuanto tal..$^{8}$

El sistema penal, violento por definición, representa el talón de Aquiles de los estados democráticos, conlleva violencia sobre las personas, por tanto, una contradicción con la finalidad perseguida: libertad libre de violencia, por ello, la violencia que ejerza ha de ser la mínima necesaria en sí misma, no en relación a otra, lo que excluye por supuesto la violencia excesiva como: la pena de muerte, el presidio perpetuo, las penas privativas de libertad

\footnotetext{
55 Véase: ROSS, Alf (1994), Sobre el Derecho y la justicia, Editorial Universitaria de Buenos Aires, Argentina.

${ }^{56}$ BUSTOS RAMÍREZ, Juan (2010), "Política criminal y estado”, en: Revista ciencias penales, disponible en: http://www.cienciaspenales.org/REVISTA\%2012/BUSTOS12.htm, consulta 10 julio de 2010, p. 1.

57 Idem.

${ }^{58} \mathrm{Idem}$. Es por eso que una política criminal referida a la seguridad pública como condición básica de libertad no puede servir para afectarla. Baratta, Alessandro (1985), "Requisitos mínimos del respeto de los derechos humanos en la ley penal”, en Nuevo Foro Penal. La seguridad pública no puede esgrimirse, como en la exposición de motivos de las reformas constitucionales en materia penal de 2008 en México, para enfrentar situaciones de emergencia y justificar violación a los derechos de los habitantes.
} 
largas y la disminución de garantías, por el contrario, hay que privilegiar formas alternativas al control penal, no prima facie, sino ultima ratio.

Sin embargo de las aportaciones de Rawls ${ }^{59}$ que han revitalizado el contractualismo como criterio legitimador del orden social y de las contribuciones de Ferrajoli ${ }^{60}$ al constitucionalismo contemporáneo, en algunas sociedades actuales, entre ellas la mexicana, se han asumido contingentemente sus contenidos, alejándose de los planteamientos kantianos que fundamentaron la teoría clásica del contrato social. Entre los principios rectores de una intervención penal garantista que se han vulnerado en el diseño y aplicación de la política criminal contemporánea, resaltan entre otros: utilidad, intervención mínima, neutralización de la víctima y mínima lesividad.

Un sistema penal, dirigido sólo por pretensiones preventivo generales y de prevención especial negativa, tal como se perfila la política criminal nacional describe un sistema penal de terror, en donde la preocupación se centra en la eficacia, el sometimiento y obediencia ciudadana.

Para finalizar, Estado que se suponga democrático ha de orientar la política criminal hacia el garantismo, en términos de Ferrajoli:

Las garantías — no sólo penales- son vínculos normativos idóneos para asegurar efectividad de los derechos subjetivos y más en general a los principios axiológicos sancionados por las leyes, en el derecho penal donde tutelan la libertad del ciudadano frente a las prohibiciones indeterminadas y a las condenas arbitrarias [...] En todos los casos la elaboración de las garantías, es decir, de los mecanismos institucionales dirigidos a asegurar la máxima correspondencia entre normatividad y efectividad en la tutela o en la satisfacción de los derechos, constituye la tarea más importante y difícil tanto de una teoría como de una política garantista del derecho. Se comprende que así entendido el garantismo no tiene nada que ver con el mero legalismo, formalismo o procesalismo. Antes bien, consiste en la tutela de los derechos fundamentales; los cuales — de la vida a la libertad, de las libertades civiles y políticas a las expectativas sociales se subsistencia de los derechos individuales a los colectivos - representan los valores, los bienes y los intereses, materiales y prepolíticos que fundan y justifican la existencia de aquéllos 'artificios' — como los llamó Hobbes - el derecho y el Estado, cuyo disfrute por parte de todos constituye la base fundamental de la democracia. ${ }^{61}$

\footnotetext{
${ }^{59}$ RAWLS, John, Op. Cit. nota 45, p. 19.

${ }^{60}$ FERRAJOLI, Luigi (1995), Derecho y razón, teoría del garantismo penal, trad., Perfecto Andrés Ibáñez, Alfonso Ruiz Miguel, Juan Carlos Bayón Mohino, Juan Terradillos Basoco, y Rocío Cantarero Bandrés, Trotta, Madrid; (2001), El garantismo y la filosofía del Derecho, trad., Gerardo Pisarello, Alexei Julio Estada y José Manuel Díaz Martín, Serie de Teoría Jurídica y Filosofía del Derecho no. 15, Universidad Externado de Colombia, Colombia; y (2014), La Democracia a través de los Derechos. El constitucionalismo garantista como modelo teórico y como proyecto político, Trotta, Madrid, España.

${ }^{61}$ FERRAJOLI, Luigi: Derecho y razón... ibídem, pp. 28 y 29.
} 


\section{DISCUSIÓN}

De nuevo, el reconocimiento de derechos es superado con creces por la realidad, pero es indudable la necesidad de adecuarnos a las nuevas realidades y exigencias nacionales e internacionales.

Es por esto que sostenemos que hay un trabajo de fondo que debe realizarse, que el auténtico reconocimiento de que los pueblos indígenas son sujetos de derecho va de la mano de la reestructuración del pacto federal con un modelo de constitucionalismo garantista, y esto se verá traducido en un giro trascendental de la política criminal mexicana cuyo enfoque garantista permitirá el ejercicio de la jurisdicción plena a los pueblos autóctonos.

\section{FUENTES}

BIBLIOGRÁFICAS

ALEXY, Robert (2005), "Los derechos fundamentales en el Estado constitucional democrático”, trad. Alonso García Figueroa, en Neoconstitucionalismo(s), Miguel Carbonell (Comp.), Trotta, Madrid, España.

ANDRÉS IBÁÑEZ, Perfecto (2001), Ética de la función de juzgar. Ponencia expuesta en el seminario sobre "Ética de las profesiones jurídicas", organizado por la Universidad de Comillas, Madrid, disponible en: http://www.cejamericas.org/doc/documentos/ etica-funcion.pdf, consulta 30 de junio de 2009.

BARATTA, Alessandro (1985), “Requisitos mínimos del respeto de los derechos humanos en la ley penal", en: Nuevo Foro Penal.

BEAUCHOT, Mauricio (2003), Interculturalidad y Derechos Humanos, Siglo Veintiuno Editores, México.

BOBBIO, Norberto (1999), Liberalismo y democracia, trad. José F. Santillana, Fondo de Cultura Económica, Breviarios No. 476, México.

BUSTOS RAMÍREZ, Juan (2010), "Política criminal y estado”, en: Revista ciencias penales, disponible en: http://www.cienciaspenales.org/REVISTA\%2012/BUSTOS12.htm, consulta 20 de julio de 2010.

CACHUMBÉ Holgugín, Nelson (2003)), “John Rawls: La justicia como equidad”, en: Criterio Jurídico, Santiago de Cali, Colombia, $\mathrm{N}^{\circ}$ 3, pp. 7-33. disponible en: http://criteriojuridico.puj.edu.co/archivos/o9_225_nelson_cuchumbe_jhon_rawls.pdf, consulta 16 de julio de 2010.

CAMOU, Antonio, (1995), Gobernabilidad y democracia, Instituto Federal Electoral, Cuadernos de divulgación de la cultura democrática No. 6, México.

CARBONEL, Miguel (2001), "Estudio introductorio" en Cosmopolitismo, estado - nación y nacionalismo de las minorías. Un análisis crítico de la literatura reciente, KYMLICKA, Will y STRAEHLE, Christine, Universidad Nacional Autónoma de México, México 
CEBALLOS BEDOYA Nicolás (2011), "Usos indígenas del derecho en el Nuevo Reino de Granada, resistencia y pluralismo jurídico en el derecho colonial. 1750 - 1810”, Revista Estudios Socio-Jurídicos, 13 (2)

DÍAZ POLANCO, Héctor, La Rebelión Zapatista y la Autonomía, Siglo Veintiuno Editores, cuarta edición, México, 2007.

ESCALANTE BETANCOURT, Yuri, "La reforma constitucional indígena: retomando el camino", en Los Derechos indígenas y la reforma constitucional en México. 2002, México, p. 79.

FERNÁNDEZ RODRÍGUEZ, José Julio y ARGUELLO LEMUS, Jacqueline (2012), ”Aspectos constitucionales del multiculturalismo en América Latina: el caso de los pueblos indígenas", Revista Pensamiento Constitucional, 16.

FERRAJOLI, Luigi (2014), La Democracia a través de los Derechos. El constitucionalismo garantista como modelo teórico y como proyecto político, Trotta, Madrid.

Tomo 2 Teoría de la Democracia, Trotta, Madrid, España.

drid, Trotta.

, (2010) Derechos y Garantías: La ley del más débil. $7^{a}$ Edición. Ma(2006), “Criminalidad y globalización”, en. Boletín Mexicano de Derecho Comparado, No. 115, enero-abril 2006, Instituto de Investigaciones Jurídicas, UNAM, México, disponible en: http://www.juridicas.unam.mx/publica/rev/boletin/cont/115/inf/inf1o.htm, consultado el 25 de octubre de 2012.

-, (2005), "Pasado y futuro del Estado de Derecho", trad. Pilar Allegue, en: Neoconstitucionalismo(s), Miguel Carbonell, Editor, Trota. sarello, Alexei Julio Estada y José Manuel Díaz Martín, Serie de Teoría Jurídica y Filosofía del Derecho no. 15, Universidad Externado de Colombia, Colombia, 2001. to Andrés Ibáñez, Alfonso Ruiz Miguel, Juan Carlos Bayón Mohino, Juan Terradillos Basoco, y Rocío Cantarero Bandrés, Trotta, Madrid.

GÓMEZ MADRIGAL, Laura Sofía. (2012). La protección jurídica de los conocimientos tradicionales desarrollados por las comunidades indígenas en México el caso de la medicina tradicional. (Tesis doctoral inédita). Doctorado Interinstitucional de Derecho. Universidad Michoacana de San Nicolás de Hidalgo, México, 2012, pp. 7-52

GÓMEZ ROMERO, Luis (2004), “¿Jueces guerrilleros? La interpretación judicial desde la izquierda”, en: Juez, Cuadernos de investigación sobre la judicatura, Volumen II, No. 4, primavera 2004, Universidad Iberoamericana, México.

GUASTINI, Riccardo (2005), “La constitucionalización del ordenamiento jurídico: el caso italiano", en: Neoconstitucionalismo(s), Ed. Miguel Carbonell, Trota, Madrid, España. 
HOBBES, Thomas, 1651 (2003), Leviatán, Losada, Argentina.

KALA, Julio César (2005) "Perseverancia en los contenidos penales preventivos", en: Seguridad Pública. Voces diversas en un enfoque multidisciplinario, Pedro Peñaloza (Coord.), Porrúa, México.

KANT, Innmanuel 1786, (1968) Principios metafísicos de la doctrina del Derecho, selección, prólogo y notas de Arnoldo Córdoba, Universidad Nacional Autónoma de México, Dirección General de Publicaciones, Col. Nuestro Clásicos, no. 33, Serie Filosofía, México.

KUHN, T. S. 1962, (2007), Estructura de las revoluciones científicas, F.C.E., México.

LOCKE, John, 1662, (2005), Ensayos sobre el gobierno civil, Porrúa, México.

PEÑALOZA, Pedro, Coord., (2005), Coord. Seguridad Pública. Voces diversas en un enfoque multidisciplinario, Porrúa, México.

POLIMENI, Florencia, “¿Democracia representativa vs democracia participativa? La falsa disyuntiva”, en: Democracia participativa, una utopía en marcha. Reflexiones y experiencias y un análisis del caso porteño, Ricardo Romero, Comp., Red de Ciencia Política Mariano Moreno, Argentina, disponible en: http://bibliotecavirtual.clacso. org.ar/ar/libros/libros/gedep/pdf, consulta 5 de marzo de 2009.

RAWLS, John (2010) Teoría de la Justicia, trad. María Dolores Gonzáles, México, $7^{a}$ reimp., Fondo de Cultura Económica.

, (2003), "Justicia como equidad", en Revista española de control externo, Vol. 5, No 13, 2003, pp. 129-158, disponible en: http://dialnet.unirioja.es/servlet/ articulo?codigo $=1069286$, consulta 16 de julio de 2010 .

ROLLA, Giancarlo (2008), "La actual problemática de los derechos fundamentales", en: Investigaciones Jurídicas, Revista del Departamento de Investigaciones Jurídicas, Facultad de Derecho, Universidad de Guanajuato, Vols., XXII y XXIII, Nums., 80-81, Enero-Diciembre 2006, México.

ROSS, Alf (1994), Sobre el Derecho y la justicia, Editorial Universitaria de Buenos Aires, Argentina.

ROUSSEAU, Jean-Jacques 1762, (1996), El contrato social, trad. Andebeng-Abeu Alingue, Panamericana, Santa Fé de Bogotá.

SOUSA DE, Santos Boaventura (2009), Sociología jurídica crítica, Trotta/ILSA.

D.O.F., Secretaría de gobernación, México, 10, junio de 2011. 